ISSN 2326-3350

\title{
Assessment of Triticale (Triticosecale) X Bread Wheat (Triticum Aestivum) Genotypes for Drought Tolerance Based on Morpho-Physiological, Grain Yield and Drought Tolerance Indices Under Non-Irrigated and Irrigated Environments
}

Research Article

Kumar $\mathrm{S}^{1}$, Mittal R K $\mathrm{K}^{1}$, Dhiman $\mathrm{R}^{1}$, Gupta $\mathrm{D}^{2,1 *}$

${ }^{1}$ Department of Crop Improvement, CSK Himachal Pradesh KrishiVishvavidhyalaya Palampur-176 062, India.

${ }^{2}$ Department of Agriculture and Food Systems, University of Melbourne, Dookie Campus, 3647, Australia.

\begin{abstract}
Wheat being important staple crop urges the need to evaluate and develop new drought-tolerant varieties to sustain its productivity under changing climatic conditions. Therefore, this study was conducted to assess the differential morpho-physiological, grain yield and drought tolerance indices responses of 27 triticale $\mathrm{x}$ bread wheat genotypes along with eight checks under non-irrigated and irrigated environments in randomized complete block design with three replications. Data on 12 important morpho-physiological and grain yield related traits along with revealed sufficient variability under two environments. Among various traits magnitude of heritability and genetic advance indicated that selection of flag-leaf area, spikes per plant and 1000-grain weight could respond to higher grain yield under non-irrigated environment.

Seedling stage traits viz., germination percentage, root length, shoot length, seedling vigour index (SVI) and germination index (GI) under normal $(0 \mathrm{bar})$ and simulated water stress with Polyethylene glycol at -8 bar indicated greater sensitivity of the genotypes to water stress. Five drought tolerance indices viz.,drought susceptibility index (DSI), tolerance index (TOL), stress tolerance index (STI), yield index (YI) and yield stability index (YSI) were also calculated to identify drought tolerant and stable genotypes based on their yields under two environments. Minimum value of DSI, TOL and yield reduction and maximum value of YSI were in harmony with each other to categorized RL 135-P1 RL 22-144 A, RL-110-1P1, RL 128-1 P1 and RL 118-P1 as top five promising drought tolerant and yield stable genotypes. These genotypes could potentially be utilized for drought tolerance wheat breeding program.
\end{abstract}

Keywords: Bread Wheat; Triticale; Drought Tolerance Indices; Variability; Heritability; Yield.

\section{*Corresponding Author:}

Dorin Gupta,

University of Melbourne, Australia.

E-mail: dorin.gupta@unimelb.edu.au

Received: April 26, 2.14

Accepted: May 17, 2014

Published: May 19, 2014

Citation: Kumar S, Mittal R K, Dhiman R, Gupta D (2014) Assessment of Triticale (Triticosecale) X Bread Wheat (Triticum Aestivum) Genotypes for Drought Tolerance Based on Morpho-Physiological, Grain Yield and Drought Tolerance Indices Under Non-Irrigated and Irrigated Environments. Int J Food Sci Nutr Diet. 3(5), 115-121. doi: http://dx.doi. org $/ 10.19070 / 2326-3350-1400023$

Copyright: S. Kumar ${ }^{\circledR} 2014$ This is an open-access article distributed under the terms of the Creative Commons Attribution License, which permits unrestricted use, distribution and reproduction in any medium, provided the original author and source are credited.

\section{Introduction}

Common wheat (Tiriticum aestivum) is one of the most important staple food cropsaccounting for 215.5 million hectares cultivated area with a corresponding production of 670.9 million metric tons worldwide[1]. In spite of the fact that we are producing enough to feed the world, recent food crisis has raised alarms to retrospect the sustainability of existing food production systems and crop yield potential under changing climatic conditions to produce enough to meet out the dietary requirements of the growing hu- man population.

India has seen a remarkable growth in wheat production during 'green revolution due to high yielding wheat varieties, expansion of cultivable land and maximum use of input sources. However, the input sources being finite are exhausting and also have repercussions in the form of degradation of production environments. To continue the wheat production momentum in India and other parts of the world being challenged with changing climatic conditions, deteriorating soil quality and decrease in cultivable land area, it is important to breed wheat cultivars with increased yield potential and tolerance to various stresses [2]. However, changing conditions will disturb monsoon patterns and will increase flooding/drought in Asia, expected to affect 25 percent of the world cereal production [3]. Among various abiotic stresses, drought is the most important stress for cereal crops limiting crop production and yield worldwide [4]. All these stresses reduce biosynthetic capacity of the plants and further might cause some destructive damages to plants [5]. However, the impacts of these stresses on plants are influenced by genotype, crop growth stage, time, duration, intensity and frequency of stress along with plant and soil interactions $[4,6]$.

It emphasizes the need to incorporate drought tolerance as one of the major objective for most of the cereal crop breeding programs, with a key focus in arid and semi-arid areas of the world [7]. At the same time, rapidly depleting genetic variability in major crops including bread wheat has necessitated the exploration of related species for its improvement. Of the various relatives of wheat, rye (Secale cereale L.), is the most useful, being a reservoir of 
valuable genes conferring tolerance to biotic and abiotic stresses and large number of spike lets, better nutritive quality (high protein and lysine) and deeper and fine root system, which can be incorporated into wheat using triticale ( $x$ Triticosecale Wittmack) as a bridge $[8,9]$. Like other crops, wider genetic diversity in wheat breeding program is desirable to meet and sustain the existing and future needs of higher production under changing climatic conditions.

Bread wheat has shown improved adaptively, stress tolerance and yield potential due to wheat-rye translocations [10-13]. There is a great challenge for wheat breeders to select and utilize promising breeding lines which perform better under stress environments. Plant stress tolerance cannot be judged solely based on its yield performance. To have effective breeding strategy for stress tolerance it is important to identify such morphological and physiological traits which are easy to identify and contribute to the final yield under stress conditions. A physiological approach is one of the useful way to develop/select new varieties rapidly [14,15] yield being important trait, appropriate understanding of processes contributing to higher yields is crucial when breeding objective is to develop varieties for specific environments [16]. Further to ascertain the selection of suitable genotypes, comparative yield performance of genotypes under contrasting environments for uncertain rain fed situations is considered first important starting point [17]. Based on the yield performance of genotypes under contrasting environments, various drought tolerance indices have been proposed for selecting desirable genotypes. Among many, drought susceptibility index (DSI) [18] measures yield stability in contrasting environments. It was suggested that DSI value greater than 1 indicates drought susceptibility [19]. The stress tolerance (TOL) was defined as the difference in yield between the nonirrigated (Ys) and irrigated (Yp) environments [20].

Later, stress tolerance index (STI) was defined as an advanced index to identify suitable genotypes with higher yields under contrasting environments [21]. The yield index (YI) and yield stability index (YSI) $[22,23]$ helped to distinguish genotypes expressing uniform yield superiority in contrasting environments from others which show superiority only in one environment.

A number of elite wheat lines/genotypes with distinct rye traits developed at CSK Himachal Pradesh Agriculture University (CSKHPAU) Palampur, have important variation for yield, biotic and abiotic stress tolerance (drought, cold and diseases) and grain quality (higher protein and lysine content).

Keeping in view, the importance of these breeding lines, the present study was aimed to know the relative sensitivity of different plant traits to the drought tolerance and further to screen out drought tolerant genotype (s) to be utilized directly as drought tolerant variety or desirable genotype (s) for future breeding program.

\section{Materials and Methods}

\section{Experimental design and plant material}

Twenty seven triticale $\mathrm{x}$ bread wheat genotypes along with eight checks were raised separately in the field under non-irrigatedand irrigated environmental conditions in Randomized Complete Block Design with three replications at experimental farm of Department of Crop Improvement, CSK HPAU Palampur (elevation $1300 \mathrm{~m}$ amsl, latitude $32^{\circ} 6^{\prime} \mathrm{N}$ and longitude $76^{\circ} 3^{\prime} \mathrm{E}$ ) follow- ing the recommended package of agronomic and plant protection practices.Each plot hadtwo rows, $2 \mathrm{~m}$ long with row $\mathrm{x}$ row and plant $x$ plant spacing of $23 \mathrm{~cm}$ and $5 \mathrm{~cm}$, respectively. The irrigated experimental plot was given three irrigations at three important crop developmental stages viz. late jointing, flowering and grain filling stages. Whereas, the experimental plot under non-irrigated condition was devoid of irrigation.

\section{Field experiment}

Data were recorded on ten important plant traits viz; grain yield/ plant, days to heading, days to maturity, flag-leaf area, plant height, spikes/plant, spikelets/spike, 1000-grain weight, biological yield/ plant and harvest index (HI) alongwith excised leaf water loss/ retention (ELWL) (\%) and drought susceptibility index(s) (SDI) and leaf area index (LAI).

Drought tolerance indices were calculated using the formulas given by various researchers

Drought Susceptibility Index $(\mathrm{DSI})=\mathrm{A}=[1-(\mathrm{Ys} / \mathrm{Yp})] /[1-(\mathrm{Ys} / \mathrm{Yp})]$

Stress tolerance $($ TOL $)=$ Yp-Ys $[20]$

Low values of TOL categorize the genotypes being stable in two different environments.

Stress tolerance index STI $=(\mathrm{Yp}+\mathrm{Ys}) /\left(\mathrm{Yp}^{2}\right)[21]$

Drought tolerant genotypes exhibits high STI values

Yield index $(\mathrm{YI})=\mathrm{Ys} / \mathrm{Ys}[22]$

Higher value of YI categorized genotypes as stable genotypes over two environments

Yield stability index $(\mathrm{YSI})=\mathrm{Ys} / \mathrm{Yp}[23]$

Higher values of YSI categorized the genotypes as stable ones in contrastingenvironments.

Where,

Ys $=$ grain yield of the genotype under non-irrigated environment,

$\mathrm{Yp}=$ grain yield of the genotype under irrigated environment, $\mathrm{Ys}$ and $\mathrm{Yp}=$ mean yields of all genotypes under non-irrigated and irrigated environments, respectively,

\section{Laboratory experiment}

Twenty seven genotypes along with eight checks were evaluated for germination and seedling characters on filter paper in $25 \mathrm{~cm}$ diameter petri-dishes at a constant temperature of $25+1^{\circ} \mathrm{C}$. The genotypes were evaluated under twolevels of moisture stress i.e., normal (O) and -8 bar [24,25]. Polyethylene glycol-6000 (PEG$6000)$ solution was prepared and used to simulate drought stress conditions [26]. PEG-6000 is recommended byseveral workersas it has property to not penetrate into the seeds as well as it is non toxic [27].

\section{Statistical analysis}

Analysis of variance for each trait was done on the basis of the linear model [28], while the combined analysis of variance over environments for grain yield was also worked out [29]. Differ- 
ent variability parameters along withgenotypic (GCV), phenotypic (PCV) and environmental (ECV) coefficients of variation, expected genetic advance (GA) and heritability in broadsense were also calculated $[30,31]$.

\section{Results and Discussion}

The combined analysis of variance over two environments (nonirrigated and irrigated) explained significant difference $(\leq 0.05)$ among genotypes (owing to their diverse nature), environments (indicating differences due to different moisture conditions) and genotype $x$ environment interactions $(\mathrm{G} x \mathrm{E})$ for all the traits, except days to heading, days to maturity, plant height and biological yield(differential response of the genotypes under different environments) (Table 1). This would mean that evaluation of these

Table 1 Combined analysis of variance (mean squares) for different morpho-physiological and grain yield traits over non-irrigated and irrigated environments

\begin{tabular}{|l|l|l|l|l|}
\hline Traits & Environments & \multicolumn{1}{|c|}{ Genotype } & \multicolumn{1}{|c|}{ G x E } & \multicolumn{1}{|c|}{ Error } \\
\hline Grain yield/plant & $256.66^{*}$ & $8.51^{*}$ & $2.33^{*}$ & 1.10 \\
\hline Days to heading & $302.50^{*}$ & $155.06^{*}$ & 4.37 & 4.15 \\
\hline Days to maturity & $1569.00^{*}$ & $81.11^{*}$ & 9.56 & 13.83 \\
\hline Flag-leaf area & $588.63^{*}$ & $131.91^{*}$ & $2.17^{*}$ & 0.89 \\
\hline Leaf area index & $5.97^{*}$ & $0.48^{*}$ & $0.14^{*}$ & 0.02 \\
\hline Plant height & $1991.50^{*}$ & $337.44^{*}$ & 12.64 & 14.08 \\
\hline Spikes/plant & $46.67^{*}$ & $2.69^{*}$ & $0.46^{*}$ & 0.25 \\
\hline Spikelets/spike & $200.31^{*}$ & $18.45^{*}$ & $1.36^{*}$ & 0.89 \\
\hline 1000-grain weight & $261.48^{*}$ & $178.56^{*}$ & $1.62^{*}$ & 0.09 \\
\hline Biological yield/plant & $1232.53^{*}$ & $82.91^{*}$ & 14.63 & 14.10 \\
\hline Harvest index & $392.56^{*}$ & $7.73^{*}$ & $6.31^{*}$ & 3.39 \\
\hline
\end{tabular}

Table 2

\begin{tabular}{|c|c|c|c|c|c|c|c|c|}
\hline Trait & Environ-ments & Range & Mean & $\%$ decrease & PCV $(\%)$ & GCV $(\%)$ & $h^{2}$ bs $(\%)$ & GA $(\%)$ \\
\hline \multirow[t]{2}{*}{ Grain yield/plant $(\mathrm{g})$} & E1 & $5.47-10.20$ & 7.45 & 22.98 & 16.60 & 14.46 & 75.82 & 25.93 \\
\hline & E2 & $6.80-12.70$ & 9.66 & & 19.53 & 13.58 & 48.31 & 19.43 \\
\hline \multirow[t]{2}{*}{ Days to heading } & E1 & $101.00-117.67$ & 111.40 & 2.10 & 4.81 & 4.35 & 82.00 & 8.13 \\
\hline & E2 & 102.33-123.33 & 113.80 & & 4.81 & 4.55 & 89.58 & 8.87 \\
\hline \multirow[t]{2}{*}{ Days to maturity } & E1 & $142.33-159.33$ & 152.45 & 3.46 & 3.07 & 2.44 & 63.50 & 4.00 \\
\hline & E2 & $147.33-163.00$ & 157.91 & & 3.28 & 1.69 & 26.57 & 1.80 \\
\hline \multirow[t]{2}{*}{ Flag leaf area $\left(\mathrm{cm}^{2}\right)$} & E1 & $6.67-25.80$ & 13.99 & 19.27 & 31.74 & 30.91 & 93.65 & 61.22 \\
\hline & E2 & $9.57-31.27$ & 17.33 & & 29.51 & 29.21 & 97.97 & 59.58 \\
\hline \multirow[t]{2}{*}{ Leaf area index } & E1 & $1.34-2.24$ & 1.72 & 16.09 & 14.24 & 11.63 & 66.67 & 19.55 \\
\hline & E2 & $1.53-3.00$ & 2.05 & & 28.02 & 12.91 & 21.21 & 12.24 \\
\hline \multirow[t]{2}{*}{ Plant height $(\mathrm{cm})$} & E1 & $62.47-95.00$ & 74.71 & 7.61 & 10.52 & 9.66 & 84.40 & 18.29 \\
\hline & E2 & $68.53-102.67$ & 80.86 & & 10.61 & 9.18 & 74.85 & 13.24 \\
\hline \multirow[t]{2}{*}{ Spikes/plant } & E1 & $1.80-4.73$ & 3.12 & 23.39 & 26.43 & 21.26 & 64.71 & 35.23 \\
\hline & E2 & $2.47-5.53$ & 4.06 & & 20.45 & 16.50 & 63.77 & 27.14 \\
\hline \multirow[t]{2}{*}{ Spikelets/spike } & E1 & $11.45-20.31$ & 15.02 & 11.49 & 12.77 & 10.63 & 69.29 & 18.23 \\
\hline & $\mathrm{E} 2$ & $12.00-21.53$ & 16.97 & & 11.95 & 10.95 & 83.94 & 20.65 \\
\hline \multirow[t]{2}{*}{ 1000-grain weight $(\mathrm{g})$} & E1 & $23.42-42.40$ & 31.86 & 6.54 & 17.22 & 17.19 & 99.63 & 35.35 \\
\hline & E2 & $25.12-44.47$ & 34.09 & & 16.08 & 16.06 & 99.73 & 37.47 \\
\hline \multirow[t]{2}{*}{ Biological yield/plant (g) } & E1 & $20.67-34.67$ & 26.55 & 15.42 & 13.92 & 10.81 & 60.37 & 17.30 \\
\hline & E2 & $21.72-41.50$ & 31.39 & & 19.56 & 12.29 & 39.49 & 15.91 \\
\hline \multirow[t]{2}{*}{ Harvest index (\%) } & E1 & $24.67-30.97$ & 28.01 & 8.88 & 8.47 & 4.74 & 31.21 & 5.45 \\
\hline & E2 & $28.31-32.83$ & 30.74 & & 6.13 & 2.62 & 18.30 & 2.31 \\
\hline Initial water content $(\%)$ & E1 & $142.67-236.33$ & 170.61 & - & 14.52 & 12.98 & 79.94 & 40.80 \\
\hline ELWL in 24 hrs (\%) & E1 & $61.00-83.33$ & 71.20 & 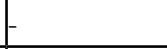 & 9.46 & 6.95 & 66.23 & 12.91 \\
\hline ELWL in $24-48$ hrs (\%) & E1 & $14.33-34.00$ & 23.74 & - & 39.63 & 26.52 & 57.89 & 31.62 \\
\hline ELWR after 48 hrs (\%) & E1 & $1.67-6.67$ & 4.14 & - & 45.31 & 27.00 & 35.51 & 33.15 \\
\hline
\end{tabular}


Table 3 Analysis of variance for germination and seedling traits under stress and non-stress environments

\begin{tabular}{|l|l|l|l|l|}
\hline Traits & \multicolumn{4}{|c|}{ Mean squares } \\
\hline & \multicolumn{1}{|c|}{ Genotypes } & \multicolumn{1}{|c|}{ Stress level } & \multicolumn{1}{|c|}{ G x S } & \multicolumn{1}{c|}{ Error } \\
\hline Germination & $200.58^{*}$ & $64384.72^{*}$ & $74.58^{*}$ & 3.70 \\
\hline Root length & $3.88^{*}$ & $1663.59^{*}$ & $3.70^{*}$ & 0.45 \\
\hline Shoot length & $7.67^{*}$ & $4664.93^{*}$ & $4.90^{*}$ & 0.39 \\
\hline SVI & $107224.90^{*}$ & $125912400.00^{*}$ & $70754.35^{*}$ & 3202.67 \\
\hline GI & $78.11^{*}$ & $4092.23^{*}$ & $37.50^{*}$ & 0.33 \\
\hline
\end{tabular}

$*$ Significant at $\mathbf{P} \leq 0.05$

Table 4 Mean, range and variability parameters for germination and seedling traits under stress (E1) and non-stress (E2) environments

\begin{tabular}{|l|l|l|l|l|l|l|l|l|}
\hline \multicolumn{1}{|c|}{ Trait } & Environ-ments & \multicolumn{1}{|c|}{ Range } & Mean & \% decrease & PCV (\%) & GCV (\%) & \multicolumn{1}{c|}{$\mathbf{h}^{2} \mathbf{b s} \mathbf{( \% )}$} & GA (\%) \\
\hline Germination (\%) & E1 & $23.33-54.98$ & 39.62 & 53.57 & 21.52 & 21.19 & 96.95 & 42.97 \\
\hline & E2 & $64.99-96.66$ & 82.50 & & 10.05 & 9.66 & 92.57 & 19.16 \\
\hline Root length (cm) & E1 & $2.43-6.74$ & 4.91 & 58.24 & 23.34 & 21.70 & 86.47 & 41.58 \\
\hline & E2 & $9.00-15.23$ & 11.83 & & 14.41 & 12.50 & 75.26 & 22.36 \\
\hline Shoot length (cm) & E1 & $1.39-7.34$ & 3.94 & 74.69 & 40.19 & 39.21 & 95.14 & 78.78 \\
\hline & E2 & $12.24-19.54$ & 15.45 & & 13.26 & 12.17 & 84.29 & 23.03 \\
\hline SVI & E1 & $141.44-541.65$ & 343.11 & 84.68 & 26.99 & 24.47 & 97.90 & 54.43 \\
\hline & E2 & $1527.38-2828.58$ & 2239.82 & & 12.91 & 12.42 & 92.55 & 24.61 \\
\hline GI & E1 & $5.03-18.96$ & 12.60 & 46.18 & 32.63 & 32.39 & 98.57 & 66.24 \\
\hline & E2 & $13.40-42.06$ & 23.41 & & 27.43 & 27.29 & 98.98 & 55.93 \\
\hline
\end{tabular}

Table 5 Mean grain yield (irrigated and non-irrigated environments), percent yield reduction and drought tolerance indices of genotypes

\begin{tabular}{|c|c|c|c|c|c|c|c|c|}
\hline Genotypes & Ys & Yp & $\%$ reduction in yield & DSI & TOL & YI (Ys/mean Ys) & YSI & STI \\
\hline RL 104-2P & $8.29(22)$ & $10.13(19)$ & $18.16(15)$ & $0.79(15)$ & $1.84(15)$ & $1.11(23)$ & $0.82(13)$ & $0.90(23)$ \\
\hline RL 110-22 & $8.81(27)$ & $10.20(21)$ & $13.63(9)$ & $0.59(9)$ & $1.39(9)$ & $1.18(27)$ & $0.86(19)$ & $0.96(25)$ \\
\hline RL 111-1-22 & $6.79(10)$ & $9.28(14)$ & $26.83(20)$ & $1.17(19)$ & $2.49(19)$ & $0.91(10)$ & $0.73(8)$ & $0.68(13)$ \\
\hline RL 111-P & $7.78(18)$ & $10.22(22)$ & $23.87(18)$ & $1.04(18)$ & $2.44(18)$ & $1.04(18)$ & $0.76(10)$ & $0.85(21)$ \\
\hline RL 114-P 2 & $5.73(2)$ & $10.39(25)$ & $44.85(26)$ & $1.96(26)$ & $4.66(26)$ & $0.77(2)$ & $0.55(1)$ & $0.64(11)$ \\
\hline RL 115-1 $P_{1}$ & $6.34(7)$ & $8.49(8)$ & $25.32(19)$ & $1.23(20)$ & $2.15(20)$ & $0.85(7)$ & $0.75(9)$ & $0.58(5)$ \\
\hline RL 115-22 & $7.90(19)$ & $10.16(20)$ & $22.24(17)$ & $0.97(17)$ & $2.26(17)$ & $1.06(19)$ & $0.78(11)$ & $0.86(22)$ \\
\hline RL 115-P & $7.42(16)$ & $8.84(10)$ & $16.06(14)$ & $0.70(14)$ & $1.42(14)$ & $1.00(16)$ & $0.84(15)$ & $0.70(15)$ \\
\hline RL 116-1 $P_{1}$ & $6.86(11)$ & $8.57(9)$ & $19.95(16)$ & $0.87(16)$ & $1.71(16)$ & $0.92(12)$ & $0.80(12)$ & $0.63(10)$ \\
\hline RL 118-P 1 & $5.98(4)$ & $6.53(1)$ & $8.42(5)$ & $0.37(5)$ & $0.55(5)$ & $0.80(4)$ & $0.92(25)$ & $0.42(1)$ \\
\hline RL 123-2 $P_{2}$ & $8.30(23)$ & $9.48(15)$ & $12.45(7)$ & $0.54(7)$ & $1.18(7)$ & $1.11(22)$ & $0.88(22)$ & $0.84(20)$ \\
\hline $\mathrm{RL}_{124-\mathrm{P}_{1}}$ & $7.75(17)$ & $9.11(12)$ & $14.93(11)$ & $0.65(11)$ & $1.36(11)$ & $1.04(17)$ & $0.85(17)$ & $0.76(17)$ \\
\hline RL 126-P & $5.90(3)$ & $10.74(26)$ & $45.07(27)$ & $1.96(27)$ & $4.84(27)$ & $0.79(3)$ & $0.55(2)$ & $0.68(14)$ \\
\hline RL 128-1 $P_{1}$ & $8.25(21)$ & $9.00(11)$ & $8.33(4)$ & $0.36(4)$ & $0.75(4)$ & $1.11(21)$ & $0.92(24)$ & $0.80(18)$ \\
\hline RL 129-2 $P_{1}$ & $8.48(25)$ & $10.00(18)$ & $15.20(12)$ & $0.66(12)$ & $1.52(12)$ & $1.14(25)$ & 0.85 (18) & $0.91(24)$ \\
\hline RL 131-P & $8.69(26)$ & $10.30(24)$ & $15.63(13)$ & $0.68(13)$ & $1.61(13)$ & $1.17(26)$ & $0.84(14)$ & $0.96(26)$ \\
\hline RL 135-P & $6.37(8)$ & $6.80(2)$ & $6.32(1)$ & $0.28(1)$ & $0.43(1)$ & $0.86(8)$ & $0.94(27)$ & $0.46(3)$ \\
\hline RL 136-1-1 & $8.14(20)$ & $9.54(16)$ & $14.68(10)$ & $0.64(10)$ & $1.40(10)$ & $1.09(20)$ & $0.85(16)$ & $0.83(19)$ \\
\hline RL 14-1 & $7.10(14)$ & $8.19(7)$ & $13.31(8)$ & $0.58(8)$ & $1.09(8)$ & $0.95(14)$ & $0.87(20)$ & $0.62(7)$ \\
\hline RL 141-2P ${ }_{3}$ & $6.95(13)$ & $7.86(5)$ & $11.58(6)$ & $0.51(6)$ & $0.91(6)$ & $0.93(13)$ & $0.88(21)$ & $0.59(6)$ \\
\hline RL 146-5 $P_{3}$ & $8.42(24)$ & $12.69(27)$ & $33.65(24)$ & $1.47(24)$ & $4.27(24)$ & $1.13(24)$ & $0.66(4)$ & $1.14(27)$ \\
\hline RL 22/125-1 & $5.47(1)$ & $7.63(4)$ & $28.31(21)$ & $1.23(21)$ & $2.16(21)$ & $0.73(1)$ & $0.72(7)$ & $0.45(2)$ \\
\hline RL 22-111 B & $6.26(6)$ & $9.27(13)$ & $32.47(22)$ & $1.42(22)$ & $3.01(22)$ & $0.84(6)$ & $0.68(6)$ & $0.62(8)$ \\
\hline RL 22-144 A & $6.88(12)$ & $7.43(3)$ & $7.40(2)$ & $0.32(2)$ & $0.55(2)$ & $0.92(11)$ & $0.93(26)$ & $0.55(4)$ \\
\hline RL 22-144 B & $6.03(5)$ & $10.27(23)$ & $41.29(25)$ & $1.80(25)$ & $4.24(25)$ & $0.81(5)$ & $0.59(3)$ & $0.66(12)$ \\
\hline RL 84-1 & $6.57(9)$ & $9.87(17)$ & $33.43(23)$ & $1.46(23)$ & $3.30(23)$ & $0.88(9)$ & $0.67(5)$ & $0.70(16)$ \\
\hline RL-110-1P & 7.34 (15) & $8.00(6)$ & $8.25(3)$ & $0.36(3)$ & $0.66(3)$ & $0.98(15)$ & $0.92(23)$ & $0.63(9)$ \\
\hline
\end{tabular}


genotypes over environments give a more accurate estimate of their yield potential.

Many researchers reported that under non-irrigated environment various agro-morphological and physiological traits were significantly affected $[32,33,34,35,36]$. Similarly, in this study various traits exhibited reduction in mean values as a result of the moisture stress in non-irrigated environment, maximum reduction was observed for spikes per plant $(23.39 \%)$, followed by grain yield per plant $(22.98 \%)$, flag leaf area $(19.27 \%)$, LAI (16.09\%), biological yield per plant $(15.42 \%)$ and spikelets per spike $(11.49 \%)$ (Table 2). However, the moisture stress caused less than 10 per cent reduction in days to heading, days to maturity, plant height, 1000-grain weight and harvest index. Delay in flowering under moisture stress has also been reported earlier [37].

To formulate an effective breeding program among various genetic parameters phenotypic coefficient of variation (PCV) and genotypic coefficient of variation (GCV), genetic advance (GA) and broad sense heritability helps to measure the genetic improvement of any crop. Yield being one of the most complex traits and highly influenced by environmental conditions emphasizes the need to ascertain high heritability and genetic advanceof desirable traits to practice their selection for crop improvement. Estimates of degree of heritability are indicative of true phenotypic expression of its genotype [38].

PCV and GCV were moderate for grain yield per plant, spikelets per spike, 1000 grain weight and biological yield per plant in both the environments (Table 2). However, high PCV and GCV were recorded for flag-leaf area under both the environments, whereas, for spikes per plant and ELWR after 48 hours under non-irrigated environment only. These high values suggested that selection based upon these traits could be reliable as their phenotypes are good reflection of their genotypes. Different researchers have reported high PCV and GCV for different traits in wheat viz., number of tillers per plant, plant height, biological yield, harvest index, 1000-grain weight and grain yield [39,40,41]. However, days to flowering, days to maturity, and harvest index under both the environments and ELWL after 24 hours under non-irrigated environment had low PCV and GCV indicating environmental influence and low prospects of selection. The magnitude of PCV was higher than the corresponding GCV, however most of the traits had very less difference with respect to their PCV and GCV values, similar results were reported by previous researchers $[42,43]$. High heritability accompanied with high GA indicates that additive gene effects mainly influence the traits and selection therefore, may be effective. Among various traits, flag-leaf area in both the environments exhibited high heritability and GA. High heritability coupled with moderate GA was observed for 1000 -grain weight under both the environments. Grain yield per plant revealed moderate heritability $(75.82 \%)$ and GA(25.93\%) under non-irrigated environment, however low heritability and genetic advance under irrigated environment. Moderate heritability and low GA were observed for days to maturity, LAI, spikelets per spike and biological yield per plant under non-irrigated environment and for plant height in irrigated environment. Low heritability and moderate GA for ELWR at anthesis stage (after 48 hours) were also observedby various workers $[44,45,46]$.

Low heritability and moderate GA for ELWR at anthesis stage (after 48 hours) suggested that selection for this trait would be more effective during vegetative phase. The water retention is only beneficial under drought conditions [47].
Considering the magnitude of heritability and GA of various plant traits, selection for flag-leaf area, spikes per plant and 1000-grain weight may be effective to increase grain yield under water stress.

\section{Laboratory studies}

Laboratory experiment revealed significant genotypic difference as well as differential response of the genotypes to different stress levels for the traits like germination percentage, root length, shoot length, seedling vigour index (SVI) and germination index (GI) under normal and water stressed conditions through analysis of variance for different traits at 0 bar and -8 bar (Table 3). Similar results were reportedby earlier workers, where they found that the relative performance of the genotypes was variable through the water stress pressures $[25,48,49]$. The ranges of mean values were generally higher under the stress environment as compared to the non-stress environment, which may be attributed due to variable expression of traits under stress conditions. Highest reduction in mean value under stress as compared to non-stress conditions were observed for SVI $(84.68 \%)$, followed by shoot length $(74.69 \%)$, root length $(58.24 \%)$, germination $(53.57 \%)$ and GI (46.18\%) (Table4). These results clearly indicated greater sensitivity of the genotypesto water stress at seedling stage and are in accordance with earlier findings [49,50]. It was suggested that under simulated drought conditions using osmotic agents, all traits related to plant development were affected, where the most susceptible traits were seedling and root length, germination, plant vigorand fresh shoot and root weight.

High PCV, GA and heritability was observed for GI under both the environments (Table 4). However, germination, root length, shoot length, SVI exhibited high PCV and GA under stress and moderate PCV and low GA under non-stress environments. Germination, shoot length and SVI were also found to be associated with high heritability under both the environments except root length, which had moderate heritability under non-stress environment. High heritability is indicative of the existence of additive factors giving a chance to improve these traits by selection. Suggesting, high genetic gain can be expected by exercising selection for traits like germination, shoot length, SVI and GA under stress. Table 5 explained relative drought tolerance of derivativesand found that among best five high yielding genotypes, RL 146-5 $\mathrm{P}_{3}$ exhibited maximum yield under irrigated environment followed by RL 126- $\mathrm{P}_{2}$ RL 114- $\mathrm{P}_{2}$, RL 131- $\mathrm{P}_{1}$ and RL 22-144 B. These genotypes could not display same ranking and yield potential in nonirrigated environment. RL 110-22 exhibited maximum yield under non-irrigated environment followed by RL 131- $\mathrm{P}_{1}$, RL 129-2 $\mathrm{P}_{1}$, RL 146-5 $\mathrm{P}_{3}$ and RL 123-2 $\mathrm{P}_{2}$. Quite interestingly, among best five high yielding genotypes, RL 131- $\mathrm{P}_{1}$ and RL 146-5 $\mathrm{P}_{3}$ had second and third rank, respectively, under non-irrigated environment in comparison to their third and first ranks, respectively, under irrigated environments. These results indicate that genotypes exhibit different yield potential based on their genotypic differences under irrigated and non-irrigated environments. It could be further explained based on their genotypic difference for drought tolerance. These results signify the important of screening genotypes under two contrasting environments to select the best among all. Similar conclusions were made by various workers who compared genotypes under two environments [51,52,53].

Further, to ascertain the selection of promising drought tolerant genotypes some drought selection indices were calculated viz., drought susceptibility index (DSI), drought tolerance index 
(TOL), stress tolerance index (STI), yield index (YI) and Yield stability index (YSI) (Table 5). RL 135- $\mathrm{P}_{1}$, RL 22-144 A, RL-110-1P, RL 128-1 $\mathrm{P}_{1}$ and RL 118- $\mathrm{P}_{1}$ had minimum DSI and TOL values and were categorized as drought tolerant genotypes. Whereas, RL 126- $\mathrm{P}_{2}$, RL 114- $\mathrm{P}_{2}$, RL 22-144 B, RL 146-5 $\mathrm{P}_{3}$ and RL 84-1had maximum DSI and TOL values and were categorized as least drought tolerant genotypes. Most of genotypes which had high DSI and TOL values also had high yields under irrigated environments. Genotypes with high TOL values indicated that they had highest reduction in yield under non-irrigated environment. The results are in accordance with other workers [53,54,55], suggesting that selection of best drought tolerant genotypes solely based on low DSI and TOL values will ascertain reduction in yield under non-irrigated environment. STI identifies and separate the high yielding genotypes under both the environments (group A) from two groups, group B and $\mathrm{C}$ which contain genotypes with relatively better yield under non-irrigated and irrigated environments, respectively [22]. RL 146-5 P 3 , RL 131-P, RL 110-22, RL 129-2 $\mathrm{P}_{1}$ and RL 104-2 $\mathrm{P}_{2}$ had maximum STI and were categories as drought tolerant genotypes. Whereas, RL 118- $\mathrm{P}_{1}$, RL 22/1251, RL 135- $\mathrm{P}_{1}$, RL 22-144 A and RL 115-1 $\mathrm{P}_{1}$ had least STI and exhibited drought susceptibility.

Further, to identify drought tolerant and yield stable genotypes, two indices viz.,YI and YSI were useful. YI ranked genotypes based on their yield under non-irrigated environment. RL 110-22, RL 131- $\mathrm{P}_{1}$, RL 129-2 $\mathrm{P}_{1}$, RL 146-5 $\mathrm{P}_{3}$ and RL 104-2 $\mathrm{P}_{2}$ had maximum YI and RL 22/125-1, RL 114-P2, RL 126-P2, RL 118-P and RL 22-144 B had least YI.

YSI could identify yield stable genotypes which exhibited least yield reduction in non-irrigated environment. Maximum YSI exhibited genotypic stability over irrigated and non-irrigated environments and was recorded by RL 135-P followed by RL 22144 A, RL 118- $\mathrm{P}_{1}$, RL 128-1 $\mathrm{P}_{1}$ and RL-110-1P. Least YSI was recorded for RL 114- $\mathrm{P}_{2}$ followed by RL 126- $\mathrm{P}_{2}$ RL 22-144 B RL 146-5 $\mathrm{P}_{3}$ and RL 84-1.

The results of different drought indices categorized RL 135- $\mathrm{P}_{1}$ RL 22-144 A, RL-110-1P, RL 128-1 $\mathrm{P}_{1}$ and RL 118- $\mathrm{P}_{1}$ as drought tolerant and stable genotypes over two environments based on least DSI, TOL, yield reduction and maximum YSI. These drought tolerance indices were in harmony with each other to predict the drought tolerant genotypes. However, the high yielding genotypes identified based on STI and YI values were RL 146$5 \mathrm{P}_{3}$, RL 131- $\mathrm{P}_{1}$, RL 110-22, RL 129-2 $\mathrm{P}_{1}$ and RL 104-2P. The identified drought tolerant genotypes are promising and can be utilized in wheat breeding program for sustaining wheat production in changing climatic conditions.

\section{References}

[1]. FAO,"Source for production data (2012) FAOSTAT database. http://faostat.fao.org/

[2]. R. Yadav, S. S. Singh, G. P. Singh and K. V. Prabhu (2010) Wheat production in India: Technologies to face future challenges. J. Agric. Sci 2:164.

[3]. S. Chakraborty, A. C. Newton (2011) Climate change, plant diseases and food security: an overview. Pl. Path 60:2-14.

[4]. J. L. Araus, G. A. Slafer, M. P. Reynolds, C. Royo (2002) Plant breeding and drought in C3 cereals: What should we breed for Ann. Bot.89: 925-940.

[5]. H. K. Lichtenthaler (1996) Vegetation stress: an introduction to the stress concept in plants. J. Pl. Physiol 148:4-14.

[6]. P. C. Saint, J. L. Crossa, D. Bonnett, S. K. Yamaguchi, M. P. Reynolds (2012) Phenotyping transgenic wheat for drought resistance.J. exp. Bot 63:1799-1808

[7]. M. A. Moustafa, L. Boersma, W. E. Kronstad (1996) Response of four spring wheat cultivars to drought stress. Crop Sci 36:982-986.
[8]. G. S. Sethi (1989) Towards the introgression of rye genes into wheat In: Review of Advances in Plant Biotechnology (Mujeeb-Kazi A and Sitch CA. eds.), 2nd International Symposium on Genetic Manipulation in Crops, Mexico, D.F., Mexico and Manila, Philippines: CIMMYT and IRRI ,145155.

[9]. N. N. Saulescu, G. Ittu, M. Ciuca, M. Ittu, G. Serban, et al. (2011) Transferring useful rye genes to wheat, using triticale as a bridge Czech J. Genet. Pl. Breed 47: S56-S62.

[10]. B. Friebe, J. H. Hatchett, R. G. Sears, B. S. Gill (1990) Transfer of Hessian fly resistance from "Cha upon" rye to hexaploid wheat via a $2 \mathrm{BS} / 2 \mathrm{Rl}$ wheatrye chromosome translocation. Theor. Appl. Genet. 79: 385-389.

[11]. B. F. Carver, A. L. Rayburn (1994) Comparisons of related wheat stocks possessing 1B or 1RS 1 BL chromosomes: Agronomic performance. Crop Sci. 34: $1505-1510$.

[12]. A. L. McKendry, D. N. Tague, K.E. Miskin (1996) Effects of T1BL・1RS on agronomic performance of soft red winter wheat. Crop Sci. 36: 844-847.

[13]. W. Kim, J. W. Johnson, R. A. Graybosch, C.S. Gaines (2003) The effect of T1DL.1RS wheat-rye chromosomal translocation on agronomic performance and end-use quality of soft wheat Cereal Res. Comm. 31:301-308.

[14]. N. C. Turner and M. E. Nicolas (1987) Drought resistance of wheat for light-textured climate. In: Drought Tolerance in Winter Cereals John Wiley and Sons, New York 203-216.

[15]. M. Lonbani, A. Arzani (2011) Morpho-physiological traits associated with terminal drought-stress tolerance in triticale and wheat. Agron. Res. 9: 315329.

[16]. A. Blum (1983) Breeding programs improving drought resistance to water stress In: Crop reaction to Water and Temperature Stresses in Humid, Temperate Climates .Westview Press, Boulder, Colorado, USA 263-275.

[17]. R. Mohammadi, M. Armion, D. Kahrizi, A. Amri (2010) Efficiency of screening techniques for evaluating durum wheat genotypes under mild drought conditions . J. Plant Prod. 4: 11-24.

[18]. R. A. Fischer, R. Maurer (1978) Drought resistance in spring wheat cultivars. I. Grain yield response Aust. J. Agric. Res. 29:897-907.

[19]. M. J. Guttieri, J. C. Stark, K. Brien, E. Souza (2001) Relative sensitivity of spring wheat grain yield and quality parameters to moisture deficit. Crop Sci. 41:327-335.

[20]. A. A. Rosielle, J. Hamblin (1981) Theoretical aspects of selection for yield in stress and non- stress environment. Crop Sci. 21: 943-946.

[21]. G. C. J. Fernandez (1992) Effective selection criteria for assessing plant stress tolerance In: Proceedings of the international symposium on adaptation of vegetable and other food crops in temperature and water stress. Taiwan 257270.

[22]. P. Gavuzzi, F. Rizza, M. Palumbo, R. G. Campaline, G. L. Ricciardi, et al. (1997) Evaluation of field and laboratory predictors of drought and heat tolerance in winter cereals. Can. J. Plant Sci. 77: 523-531.

[23]. M. Bouslama, W. T. Schapaugh (1984) Stress tolerance in soybean. Part 1: Evaluation of three screening techniques for heat and drought tolerance", Crop Sci. 24:933-937.

[24]. M. M. D. Heikal, M. A. Shaddad (1982) Alleviation of osmotic stress on seed germination and seedling growth of cotton, pea and wheat by proline", Phyton.22: $275-287$.

[25]. J. E. R. Perez, J. M. Solis, G. M. Lazcares, R. M. Aguilar, J. S. Casttellanos (2007) Wheat (Triticum aestivum L.) and triticale (X Triticosecale Witt.) germination under moisture stress induced by polyethylene glycol Afr. Crop Sci. Conf. Proc. 8: 27-32.

[26]. B. E. Michel, R. M. Kaufmann (1973) The osmotic potential of polyethylene glycol-6000 Plant Physiol. 51: 914-916.

[27]. C. J. Willenborg, J. C. Wildeman, A. K. Miller, B. G. Rossnagel, S. J. Shirtliffe (2005) Oat germination characteristics differ among genotypes, seed sizes, and osmotic potentials", Crop Sci. 45: 2023-2029.

[28]. R. A., Fisher (1954) Statistical Methods for research workers", 12thEdn. Hafner Publishing Co, NY, USA.

[29]. M. M. Verma, K. S. Gill, D. S. Virk (1987) Genotype x Environment interactions, its measurement and significance in Plant Breeding Pl. Agric. Uni. Comm. Centre, P.A.U., Ludhiana, India 3-10.

[30]. Burton, G. W, E. H. De Vane (1953) Estimating heritability in tall fescue (Festuca arundinacea L.) from replicated clonal material. Agron. J. 45: 478481.

[31]. H. W. Johnson, H. F. Robinson, R. E. Comstock (1955) Estimates of genetic and environmental variability in soybean .Agron. J. 47:314-318.

[32]. S. R. Winter, J. T. Musick, K. B. Porter (1988) Evaluation of screening techniques for breeding drought resistance winter wheat Crop Sci. 28: 512-516.

[33]. A. Blum, Y. Pnuel (1990) Physiological attributes associated with drought resistance of wheat cultivars in a Mediterranean environment Aus. J. Agric. Res 41: 799-810.

[34]. E. Acevedo, P. Q. Craufurd, R. B. Austin, P. Parezmarco (1991) Traits associated with high yield in barley in low rainfed environments. J. Agric. Sci 116: $23-36$

[35]. A. Arzani (2002) Grain yield performance of durum wheat germplasm under Iranian dryland and irrigated field conditions SABRAO. J. Breed. Genet 
34:9-18.

[36]. N. Fayaz, A. Arzani (2011) Moisture stress tolerance in reproductive growth stages in triticale (X Triticosecale Wittmack) cultivars under field conditions, Crop Breed. J. 1:1-12.

[37]. A. Blum (1988) Plant breeding for stress environments, Boca Raton Florida, USA, MN, CRC Press.

[38]. R. J. Chandrababu, R. K. Sharma (1999) Heritability estimates in almond [Prunus dulcis (Miller) D.A. Webb]", Sci. Hortic.79:237-243.

[39]. D. Desalegn, G. Bekele, Y. Balacha, A. Zewdie (1996) Grain yield response of some bread wheat cultivars in diverse environments of Ethiopia" The Ninth Reg. Wheat Workshop East. Central and Southern Africa, CIMMYT, Addis Ababa. Ethiopia, 2-6 October, 1995:387-389.

[40]. B. R. S. Krishnawat, S. P. Sharma (1998) Genetic variability in wheat under irrigated and moisture stress conditions, Field Crop Res. 16: 314 - 319.

[41]. A. Degewione, T. Dejene, M. Sharif (2013) Genetic variability and traits association in bread wheat (Triticum aestivum L.) genotypes, Inter. Res. J. Agric. Sci. 1: 19-29.

[42]. S. Kumar, V. K. Dwivedi, N. K. Tyagi (2003) Genetic variability in some metric traits and its contribution to yield in wheat (Triticum aestivum L.), Prog. Agric. 3: 152-153.

[43]. B. S. Shankarrao, S. Mukherjee, A. K. Pal, D. K. De (2010) Estimation of variability for yield parameters in Bread Wheat (Triticum aestivumL.) grown in Gangetic West Bengal, Elect. J. Plant Breed.1:764-768.

[44]. P. L. Bruckner (1986) "Evaluation of tolerance to post-anthesis drought stress in spring wheat”, Dissert. Abs. Inter. B. Sci. and Eng. 46:2880B.

[45]. I. Singh, R. S, Paroda, S. K. Sharma and R. K. Chaudhary (1987) Correlation and path analysis in wheat (Triticum aestivum L.). H.A.U. J. Res.17: 176-180.
[46]. S. K. Gupta and S. R. Verma (2000) Variability, heritability and genetic advance under normal and rainfed conditions in durum wheat (Triticum durum Desf.). Indian J. Agric. Res. 34: 122-125.

[47]. J. M. Clarke and T. N. McCaig (1982) Evaluation of techniques for screening for drought resistance in wheat, Crop Sci. 22:503-506.

[48]. A. Blum, B. Sinmena, and O. Zev (1980) An evolution of seed and seedling drought tolerance screening test in wheat", Euphytica. 29: 727-736.

[49]. A. A. Khakwani, M. D. Dennett and M. Munir (2011) Drought tolerance screening of wheat varieties by inducing water stress conditions", Songklanakarin J. Sci. Technol. 33: 135-142.

[50]. S. S. Dhanda, G. S. Sethi, and R. K. Behl (2004) Indices of drought tolerance in wheat genotypes at early stages of plant growth J. Agron. Crop Sci. 190: 1-6.

[51]. A. Gholipouri, M. Sedghi, R. S. Sharifi and N. M. Nazari (2009) Evaluation of drought tolerance indices and their relationship with grain yield in wheat cultivars", Recent Res. Sci.Technol. 1: 195-198.

[52]. J. Anwar, G. M. Subhani, M. Hussain, J. Ahmad, M. Hussain, et al. (2011) "Drought tolerance indices and their correlation with yield in exotic wheat genotypes" Pak. J. Bot. 43:1527-1530.

[53]. T.A. Yasir, X. Chen, L. Tian, A. G. Condon and Y.G. Hu (2013) Screening of Chinese bread wheat genotypes under two water regimes by various drought tolerance indices" Aust. J. Crop Sci. 7: 2005-2013.

[54]. J. M. Clarke, R. M. DePauw, T. F. Townley-Smith (1992) Evaluation of methods for quantification of drought tolerance in wheat" Crop Sci. 32:7287232.

[55]. R. Talebi, F. Fayaz, N. Naji (2009) Effective selection criteria for assessing drought stress tolerance in durum wheat (Triticum durum Desf.). Gen. Appl. Plant Physiol 35: 64-74. 